\title{
Novel resource saving interventions: the case of modelling and storytelling
}

Article

Accepted Version

Carragher, V., O'Regan, B., Peters, M. and Moles, R. (2018)

Novel resource saving interventions: the case of modelling and storytelling. Local Environment, 23 (5). pp. 518-535. ISSN 1354-9839 doi:

https://doi.org/10.1080/13549839.2018.1434493 Available at https://centaur.reading.ac.uk/76155/

It is advisable to refer to the publisher's version if you intend to cite from the work. See Guidance on citing.

Published version at: https://www.tandfonline.com/doi/full/10.1080/13549839.2018.1434493

To link to this article DOI: http://dx.doi.org/10.1080/13549839.2018.1434493

Publisher: Routledge

Publisher statement: To cite this article: Vincent Carragher, Bernadette O'Regan, Michael Peters \& Richard Moles (2018): Novel resource saving interventions: the case of modelling and storytelling, Local Environment, DOI:

10.1080/13549839.2018.1434493 To link to this article:

https://doi.org/10.1080/13549839.2018.1434493

All outputs in CentAUR are protected by Intellectual Property Rights law, including copyright law. Copyright and IPR is retained by the creators or other copyright holders. Terms and conditions for use of this material are defined in the End User Agreement. 


\section{CentAUR}

Central Archive at the University of Reading

Reading's research outputs online 


\section{Cover Page}

Paper title: Novel resource saving interventions: the case of modelling and storytelling

Corresponding Author: Vincent Carragher, Civil, Structural and Environmental Engineering, Trinity College Dublin, Dublin, Ireland. Telephone: 018962670. Email: vincentcarragher@gmail.com.

Co-author: Bernadette O'Regan, Centre for Environmental Research School of Natural Sciences, University of Limerick, Limerick, Ireland. Telephone: 061202552. Email: bernadette.oregan@ul.ie.

Co-author: Michael Peters, School of the Built Environment, University of Reading, Reading, UK. Telephone: 0118 3785266. Email:

m.d.peters@reading.ac.uk.

Co-author: Richard Moles, Centre for Environmental Research School of Natural Sciences, University of Limerick, Limerick, Ireland. Telephone: 061202817. Email: richard.moles@ul.ie.

Novel resource saving interventions: the case of modelling and storytelling Vincent Carragher, Bernadette O’Regan, Michael Peters and Richard Moles 


\section{Abstract}

Climate Change communication to the Public is in general presented in a negative fashion and often depicts the resultant costs and impacts as distant. Its substantial gloom together with the less immediate consequences significantly weaken responses. Narratives and stories are potent arbiters of meaningful communication and are an important vehicle for communication in our information rich lives. Importantly, they reduce jargon, gather and translate information, provide insight, reframe evidence and engage audiences. It has been argued by many observers that stories are potentially useful in driving change; presenting a way to value what is gone, expressing emotions, and helping us assert our determination to salvage something and work towards the future.

This paper details the methods utilised by the authors to generate stories and case studies in a community in Ireland over a 4 year research period. The aim of the work was to identify and assess the salience and potency of storytelling - as part of a 'co-creation' process - with regard to galvanising local action in the generation of sustainable models of lifestyle practice for residents. In this paper co-creation includes the planning phase of co-design and the implementation phase of co-production. The demonstration of these sustainable lifestyle practices were a strong driver for the sustainable transition of this community supporting the reduction of its ecological footprint by $28 \%$ over 4 years, evidence of which is highlighted in this paper.

\section{Keywords}

Narratives, stories, reinterpretation, co-creation, decarbonisation. 


\subsection{Introduction}

\subsection{Problem definition}

The Republic of Ireland (from here on referred to simply as 'Ireland') has the third highest greenhouse gas emissions per capita within the EU which are $45 \%$ above the EU average (CSO, 2016) and which significantly overshoot its 2020 emissions targets (EPA, 2017a) making financial penalties all but inevitable. Natural resources underpin Ireland's economy and quality of life but Ireland's extensive use of resources is the chief reason for overshooting its emissions targets. Of particular importance in this regard is the role of agriculture and transport which constitute $22.9 \%$ and $21 \%$ of the nations total GHG emissions annually (EPA, 2017a; EPA 2017b). This makes resource efficiency vital to decreasing emissions, increasing sustainability, supporting economic growth and enabling job creation. The EEA's report The European Environment - State and Outlook 2010 recognises that green economic transition is necessary but that environmental policies or economic and technology-driven efficiency gains alone will not be sufficient (EEA, 2015) to support such transition.

Policy in Ireland, such as the Local Government Reform Act, has eroded subsidiarity gradually increasing central and local Government involvement in the operation, funding and work of community and voluntary sector organisations with the rationale of alignment and efficiency. Tendering and privatisation of services leads to actors with no local connection displacing voluntary and community sector organisations. Furthermore, the views of those working in the community sector in Ireland revealed that community development workers are now spending more time desk-bound and inputting 
data on their work in order to achieve targets set by funders than actually working in communities (Forde et al, 2015).

The Irish Government's Our Sustainable Future policy (2012) proposes measures focused on sustainable consumption, production and communities. In December 2015, Ireland's Energy White Paper Ireland's Transition to a Low Carbon Energy Future 2015-2030 (DCENR, 2015) set out over 90 Government actions aimed at low carbon transition. In the Energy White Paper the Government sets out several specific actions to engage and empower communities in sustainable energy transition. The local, community level offers a potential economy of scales and provides a capacity on which to work leveraging engagement and empowerment of citizens as active participants in decision making processes and the delivery of policies and initiatives. The considerable potential of community-based intervention, aimed at relatively deep impacts on resource saving at the level of behaviour, has been reviewed by others (see for example Hori et al., 2013; Doyle \& Davies, 2013).

We estimate there exist about 30 communities in Ireland currently involved in this type of transition process: here we focus on one such example, in Ballina, County Tipperary as a case study. Ballina is a settlement (Figure 1) with a population of 2442 residents (CSO, 2012). Sixteen of the EU28 countries have lower car dependence in transport than does Ireland (Eurostat, 2014). Recent census data for Ireland confirms that Ballina residents rely more heavily on private transport than the Irish population in general, with car ownership by household approximately one fifth higher than the national average, and daily 
distances traveled almost double the average (CSO, 2016; see also Carragher, 2011, p40). The Ballina demographic represents a diversity of activities and a demographic spread that will facilitate the investigation of differing citizen perspectives and a wide range of enabling and restricting factors vis-à-vis engagement and empowerment in sustainability initiatives and transitions in Ireland.

\subsection{Purpose and line of enquiry}

Given the level of private transport dependency in Ballina it is important to avoid the low engagement and poor resource saving impact of previous interventions such as the energy efficiency Power of One scheme which was launched in Ireland in 2006. Third party assessment of such campaigns often reveal poor engagement and savings as in this case where gas consumption savings were not recorded by residents (ESRI, 2013). Similarly water agencies have tended to connect with communities with relatively lower levels of active engagement. MacKenzie (2012, p13) for example, specifically states with regard to the Irish water agencies that: "They strongly focus on providing information to participants, listing key issues and soliciting feedback on existing policies"; rather than facilitating co-creation method. Co-creation is an established management approach to solving problems jointly by multiple stakeholders which offers a process for policy design amongst other things. It includes a planning phase of co-design and the implementation phase of co-production. Such an engagement method leads to local ownership of process and action, and has proved extremely useful in relation to improving the impacts of interventions (DEFRA, 2007 \& NESC, 2013). Co-creation also has the capacity to 
support government locally and nationally in its role of encouraging behavioural change through demonstration by doing (NESC, 2012).

\section{Figure 1: Schematic map of Ballina settlement}

It is possible for methods utilising co-design and co-production techniques to generate stories and case studies which we will demonstrate in this paper can drive the generation of substantial resource savings. Adoption of this approach aims to provide an alternative to more 'conventional' interventions (including information/awareness raising campaigns) which often tend to over rely on a technical message and frequently lack effective communication of the potential benefits of participation, including the empowerment that active participation in decision making processes can enable.

The importance of generating local narrative, reinterpretation of scientific knowledge and two-way learning, through skilled facilitation, are interrelated issues highlighted by serveral observers including Lejano et al. (2013), Reed, (2008) and Satterfield et al. (2000). The methods to which they refer aim to translate technical information and its constructs to citizens making them more understandable and thereby offering a promising opportunity for catalysing sustainable transition by community members themselves. Many academics and practitioners now advocate the generation of enhanced levels of participantownership of interventions and their activities. Expert facilitation is utilised to generate such ownership and is an essential and intrinsic element of successful models of engagement. This degree of 'deep' participation can be activated by the method that is described in Beckley's 'Continuum of Public Participation' which emphasises the salience of information exchange, articulation of distinct 
interests and the ability of stakeholders to exert an influence on decision making processes and outcomes (Beckley et al., 2006). Such participation increases local support, reduces objection and has the capacity to build and strengthen social capital (Waren \& Fayden, 2010 and Munday et al., 2011). It can also serve to enhance procedural and distributional justice (Wustenagen et al., 2007).

\subsection{Scope and limitations}

This paper explores the methods utilised to generate case studies and stories, within a sustainability focused community research intervention, in order to model and assess the potency of sustainable behaviour change enabled in comparison with more conventional types of intervention. The methods focused on were one part of a basket of measures and a larger research study conducted by the University of Limerick that form the subject of ongoing research in the Energy Research Group, Trinity College Dublin. We define the methods utilised that were successful in generating potent messaging within the community leveraging storytelling and case studies in order to enhance the transition towards more sustainability over a 4 year period. In order to highlight the potential of such methods the paper provides details regarding demonstrable impact in the results section. In order to achieve this it was necessary to include a parallel intervention of surveying and measurement at the household scale to enable the recording of changes in resource use brought about by the intervention. A complementary ecological footprint measurement device was designed and its application to the test community accompanied this research intervention (Carragher, 2011, p146-188).

\subsection{Methods}


A central aim of the action research carried out for this study was to engender widespread participation and empowerment in low carbon transition within the test community by utilising stories and case studies, adopting discourse based approaches (DBAs) and leveraging co-design and co-production activities. The intention was that by incorporating co-design and co-production this would lead to the generation - and utilisation of - local narratives which would illuminate pathways to enable the practicable decarbonisation of routine living practices.

In relation to co-creation and co-management of process, Berkes (2009) discusses the importance of community bridging organisations (CBOs) and, connected to this, identification of appropriate stakeholders and their early recruitment and engagement as measures to drive participation and community ownership (Luyet et al., 2012). In this regard strategic profiling allowed selection of the appropriate test community (Ballina) which included resident CBOs that were evaluated as being potentially supportive of the intervention. As such, the identification and early recruitment of these CBOs was pivotal in enabling efficient and effective engagement of the Ballina settlement.

In this research a number of concepts and methods with similarities were applied using skilled facilitation. These were sourced in discourse based approaches (DBAs), participatory action research, adaptive management, social and situated learning, place based science and analytic deliberation. These approaches generated local narrative, reinterpretation, modelling and local and solution orientated messaging from co-design and co-production activities. 


\subsection{Discourse Based Approaches}

An important feature of the adopted method that has the capacity to engender strong participation is the incorporation of local and scientific knowledge (Reed, 2008) alongside solution oriented actions (Moser and Dilling, 2007). McNeeley and Huntington (2007) believe that talking about ways to take local actions to mitigate and adapt to climate change impacts can be effective in shifting the discourse towards one of alliance and empowerment. The power of "real-life" stories lies primarily in their ability to create an arresting message that is hard to ignore (Duffy et al., 2005). Allied to the concept of modelling, DBAs and their skilled facilitation can enable more extensive and meaningful communication, allowing groups or communities to share a conversation through stories.

In order to share a conversation, and create communication, it has been argued that participants and facilitators should co-design a structure for conversation which is designed to support and enhance two way dialogue (Moser and Dilling, 2007) and this has the ability to enable more extensive group understanding and - ultimately - consensus (Binder and Bourgeois, 2006). The importance of theskilled facilitation of engagement exercises in creating conducive environments is pinpointed as essential by Petts, (2006) and can be encouraged through both formal and informal interaction.

A significant barrier to effective resource planning and management is often the failure of researchers to exchange knowledge and understanding with local communities in meaningful and sufficiently engaging ways (Boreux et al., 2009). Scientists and other experts have frequently been afforded priority with regard 
to this pursuit and their judgement of knowledge. Place based science, however, recognises that universal science is not always "fit-for-function" and proffers alternative measures for the more complete evaluation of science's quality (Bremer and Funtowicz, 2015). It is necessary to bring public concerns into an expert discourse and to enable technical issues to be rendered more understandable. Optimisation and balance is necessary here so that both the public and experts can learn where and how the appropriate conditions for listening, sharing, reflecting on preferences and adapting can be crafted. The more experiential the learning during the community meetings, the greater its engagement qualities, interest and impact. Principles which underline good practice for engagement include (i) utilising local knowledge; (ii) citizen involvement throughout; (iii) recognising, embracing and addressing diversity of interests; (iv) building local capacity; and (v) including citizens in assessment and management where possible (Jackson et al., 2012). Such deliberative processes can enhance procedural justice and legitimacy through the building of trust; increase understanding through social learning; and promote ownership of decision-making processes (Wustenagen et al., 2007 and Hajjar \& Kozak, 2015). Important features such as trust-building and co-determination (FernandezGimenez et al., 2008; Kainer et al., 2009; Pahl-Wostl, 2006; Shackleton et al., 2009) signpost the potential for, and benefits of, community involvement in problem identification, research, modelling and monitoring. They can lead to "shared understanding among diverse participants (social learning), greater trust among parties and credibility in the findings" (Baldwin et al., 2012, p75). Related activities such as co-production and meaningful messaging can enhance interaction, generating new knowledge while progressing understanding. As 
Baldwin et al. (2012, p75) argue this leverages "an appreciation of the nature and quality of the relationships and interactions", amongst the participants, "and the combined knowledge sets they bring to the situation". In meaningful engagement, it is imperative that participants recognise that their input is valuable and makes a difference (Baldwin et al., 2012). In short Corburn (2009, p202), argues that co-production "offers a way to conceptualise how the scientific and social objectives can emerge together".

Adaptive management requires collective self-reflection through interaction and dialogue (Fernandez-Gimenez et al., 2008) and the resulting growth in understanding and skills from the collective effort of working together to improve a situation is referred to as social learning (Keen et al., 2005; Measham, 2009). Non-coercive spaces and processes can help to advance social learning amongst stakeholders "enhancing critical analysis and examination unimpeded by power or knowledge differentials" (MacKenzie et al., 2012, p11). Adaptive management and social learning share many of the characteristics of participatory action research (PAR). PAR is a form of applied research in which stakeholders take on a co-researcher role where "researchers and community stakeholders work together to co-generate (co-produce) knowledge through ongoing communicative processes and joint implementation of findings" (MacKenzie et al., 2012, p12).

Action research is typified by three recurring stages: inquiry, action, and reflection and these through iteration form the basis for continual improvement. Through inquiry, researchers and stakeholders initially identify a shared 
practical problem and agree corrective methods. A planned and structured intervention is executed in the action phase and any changes are closely monitored. The reflection stage involves both the observation of, and reflection on, the impact and effects of this action on the situation/problem. PAR provides additional engagement as it includes stakeholders in the process of evaluation. It provides the examined community with the opportunity to review and critique the research process and a major benefit is the empowerment it affords providing legacy and ownership of the methods employed for future use (MacKenzie, 2012).

Such participatory models support the co-production of sustainability plans. This usually involves the setting of clear and agreed objectives, development of data sets for sustainability analysis and prioritisation of actions through deliberation (Ramaswami et al., 2011).

\subsection{Storytelling}

Climate change discourse tends to be predominantly negative, depicting significant loss into the future as a consequence of insufficient action being taken in the short term with regard to the development and delivery of pragmatic mitigation strategies. This type of articulation can serve to put off non-experts and 'regular' citizens who may find the detail somewhat intractable and thus not amenable to immediate responses. Stories however, translate a value for such loss, providing form and structure for feelings and holding the capacity to motivate responses and action (Randall, 2009). The power of storytelling has been advocated by many researchers in recent times and indeed was adopted as a driver for behaviour change by the International Energy Agency's Task 24 
program - an on-going demand side energy efficiency initiative aiming to encourage behavioural and practice oriented changes at household and community levels. Storytelling allows for multiple perspectives, deepens levels of appreciation (Mourik et al., 2015) and allows the observer "to move beyond the presented and pretended objectivity of a more quantitative approach" (Rotmann et al., 2015, p120). The utility of storytelling however has limits including the potentially vast complexity and range of different situations which can prove problematic in terms of the assimilation and communication of clear messages (Rotmann et al., 2015).

In this research intervention, and through stories, the loss and associated feelings are embedded in local narratives and help to communicate and navigate potential pathways for sustainable transition. Narratives are important mediators of meaning making messages more easily understood using everyday language (Dunwoody, 2007). The narrative technique has a strong capacity for engaging participants representing technical information as understandable. Integrating local narrative is therefore important for success within DBA and participatory interventions (Lejano et al., 2013).

Stories are a translation tool that exist between theory and practice and are used in this research intervention as forms of narrative, evidence, knowledge and effective communication. They are useful to: (i) engage and influence audiences, (ii) gather and evaluate information, (iii) reframe evidence and provide insight, and (iv) reduce jargon and develop a common base for collaboration (Rotmann et al., 2015). Stories in relation to energy innovations can generally be classified 
into three main genres: hero stories, learning stories and horror stories (Janda and Topouzi, 2013). The use of horror stories in energy interventions tends to centre on the powerlessness caused by climate change media and the negative consequences of motivating emotional reactions such as guilt (Bingham, 2007) and fear (Moser and Dilling, 2007). Hero stories are usually structured around technology and/or stakeholder impacts. In 'learning' stories protagonists are regular people, highlighting gaps between the technical and practical potential of solutions and depicting how the socio-technical system of the built environment works (Table 1). Hero stories on the other hand describe how science predicts the system will work generally through a focus on technology (Janda and Topouzi, 2015). The Task 24 study reported in this paper utilised learning stories as a core communication device based on the reality that they are in essence a process of dialogue and co-design (Moezzi and Janda, 2014). Rotmann et al. (2015) consider the form and complexity of stories and their sources of information to be more nuanced and important than genre itself.

\section{Table 1: Genre comparison}

Dunwoody (2007) considers for the most part that in relation to communication personal experiences are superior to data. Personalised case studies are notable and such modelling of behaviour is a significant part of the learning process (Berry et al., 2014) whether through policy or community action (NESC, 2012). Bandura's subdivision for investigation of social learning is presented in Table 2. Similar to analysis by Berry et al. (2014), Table 2 also explores the utility of stories in fulfilling these social learning stages. Given the problem definition above and the difficult matters to be resolved through climate change and 
resource management responses (Garmendia and Stagl, 2010), conduits and processes for the delivery of information become at least as important as the information itself. There are numerous processes such as participatory and deliberative practices that support co-production of knowledge and social learning (Wilner et al., 2012). It is clear that upporting sustainable transition effectively requires the use of the appropriate conduits and processes and, here, stories and social learning have strong potency. The broad range of processes and facilitated events explored by the research intervention presented and discussed in this paper aims to offer ongoing opportunities for reflection and learning to support participants in their efforts to carry out low carbon behaviour as part of their routine daily lives.

\section{Table 2: Relating storytelling to Bandura's concept of social learning}

\subsection{Intervention Events and Activities}

This paper examines the storytelling leveraged by DBAs in multiple events and reports the resultant transition which supported continued low carbon behaviour. Participants were encouraged to participate using storytelling to capture their low carbon behaviour and lifestyle practices. Recordings were made in all interventions and then summaries of these stories were made and combined with metrics where feasible creating short statements or case studies. These short case studies were especially useful in reminding residents of stories, providing recognition for the subjects of the case study and providing low carbon guidance in their own right (Tables 3 and 4). Case studies, and therefore their stories, were disseminated using many community-based channels such as general project newsletters, local media coverage, parish newsletters, 
competition award ceremonies, project-based low Carbon literature, schoolbased channels, television, video, meetings, Workshops and Focus Groups.

As described earlier this research applied a number of similar methods and concepts using skilled facilitation and these were sourced in discourse based approaches (DBAs), participatory action research (PAR), adaptive management, social and situated learning, place based science and analytic deliberation. These approaches were utilised within the co-designed and co-production activities listed in Figure 2. The co-designed activities established project ownership within the community and were led by meetings between the research team, school and local community based organisations. In these meetings, the school and CBO's were concerned with their ecological footprint and therefore defined tasks and outputs which generated an annual intervention portrayed by the cycle in Figure 2. The annual intervention started each year in Spring with the carbon (ecological footprint; EF) audit and ended with final promulgation activities late in the year. The annual intervention (Figure 2) was repeated each year for four years and so the promulgation campaign of the previous year was followed by the audit phase of the following year.

\section{Figure 2: Co-creation of annual intervention events}

\subsubsection{Carbon Audit Workshops}

A novel ecological footprint (EF) methodology was created in response to the study community's concerns, which was developed upon the baseline calculations of Irish household EF carried out by the University of Limerick (see Carragher, 2011, p146-188). This was utilised in the community to calculate the ecological footprint using dedicated audit surveys and workshops. After each 
survey annual workshops were hosted by the school as well as two additional ones by other CBO's. This generated significant levels of situated learning due to the workshop providing participants with the opportunity to work through the calculations of the various EF survey categories, evaluating, amongst other things, the impact of waste practices, transport arrangements and household energy consumption. This level of participation involved co-production and drew on the method and techniques of DBAs, place based science, PAR and analytic deliberation approaches.

Workshops were implemented using a workshop plan (i.e. a discussion/activity guide) structured into several key themes. They facilitated groups, with between 15-25 participants, and were scheduled in two ways. For the school-based workshops the schedule ran each side of lunchtime usually on Saturdays and for the CBO workshops schedules were flexible but generally were convened in the evenings. Using the workshop plan the procedure and outcomes were well defined and easily achieved as the EF surveys formed the basis for the evaluations. Organisation of the workshops was guided and informed by the reviews of Slocum (2003) and Beckley et al. (2006).

\subsubsection{Low Carbon Focus Groups}

Each year, following the workshops detailed in the previous section, a series of focus groups were facilitated within the study community with discussion focusing on low carbon lifestyle practices; four of these were hosted by the school and two by other CBO's (Figure 2). The focus groups utilised the EF calculations and discussed low carbon solutions which involved further coproduction located primarily in place based science, PAR, adaptive management, 
local narrative, situated/social learning, re-interpretation approaches and solution orientated messaging. The focus groups facilitated within this research were attended by a minimum of 20 participants when school-based and never more than 30 when hosted by CBOs. Early recruitment of the CBOs allowed participants to be invited who were representative of the community and the perspectives held in the community. Those invited were based in the community's groups and living and working in the community. The workshops hosted by CBOs were on average attended by more women (60\%) and those hosted by the school were attended by more pupils (75\%).

The groups were designed to obtain information about participants' preferences pertaining to low carbon behaviour and practices in relation to the community ecological footprint context and measurement. They fostered interaction involving structured discussion within a permissive and non-threatening environment. The overall method used in designing and managing the groups was aligned to guidance provided by Slocum (2003). One of the main tasks of the facilitator in these focus groups was to motivate storytelling by participants and ensure that the stories were successfully recorded. Subsequent to the events the stories were converted to short case studies for ease of dissemination and further analysis. These stories and their case studies formed a major part of the project's communication strategy and were utilised heavily in the intervention's promulgation material. The annual focus groups encouraged and enabled the community to deliberate, relate to and reflect on its low carbon transition.

\subsubsection{Competition and Communication}


The community level ecological footprint together with low carbon solutions, both co-produced, were disseminated in various short presentations to CBOs and the school; and entries were sought to a community level competition aimed at reducing the community EF. The competition was launched annually and local sponsors provided prizes appropriate to the theme of sustainability. Competition entry formats were required to be locally narrated slogans. An example of a competition winning slogan, from a participant, which motivated decarbonisation of local transport was: 'why use a litre of petrol to buy a litre of milk'. Competition entries were utilised providing significant material based in local narrative for dissemination. The promulgation material was further enhanced utilising effective communication techniques divided into two functional categories of message framing and communication channels. The framing of a message is a critical factor in raising awareness, enabling knowledge, and translating awareness into sustainable-behaviour change. Message framing was further subdivided into (i) message contextualisation and (ii) effective messaging in order to systematically and practically enhance effective communication (Carragher, 2011 and Carragher et al., 2017). This phase of the co-production included elements of PAR, social and situated learning, local narrative, reinterpretation, place based science and solution orientated messaging.

\subsubsection{Facilitation}

Daniels and Cheng (2004) advocate the use of DBAs stressing the importance of active listening, reflection, collective action, and mutual goals and values. Participants were facilitated in this research to co-design intervention process and co-produce knowledge through inclusive DBA (Slocum, 2003; Beckley et al., 
2006 and MacKenzie, 2012). Carefully thought through - and sympathetic matching of participants (as advocated by Dryzek, 2000 and Petts, 2006 for example) was striven for in order to enhance the capacity for deliberation and active listening in a non-coercive environment. Indeed, care in this procedure is a prerequisite in the DBA utilised.

In both the workshops and the focus groups the facilitator's role involved: (i) securing progress using an event plan; (ii) inclusion of all participants; (iii) making discursive associations, and (iv) discussion encapsulation. In the focus groups an essential task was catalysing dialogue and recording stories. Where expert input was required the facilitator translated technical jargon into more meaningful terms/narrative for the various participants. The facilitator had to be aware of contextual knowledge in capturing the meaning of stories, thoughts and images. Facilitation depends upon active listening and requires a knowledge of the audience and its context. This includes how the participants' values and experiences can impact their stories (Rotmann et al., 2015). Through active listening, participants were fostered to articulate their stories using their own narrative and values. McKenzie-Mohr and Smith (2000) advocate community based social marketing and make the removal of barriers an essential factor in fostering sustainability. One of the key outcomes of the facilitated conversations was the identification of barriers to the effective delivery of local sustainability initiatives. In addition to this a range of potential approaches for addressing the barriers was also generated in each case. In many of the conversations key barriers that were identified related to a lack of knowledge and/or awareness. Similar experiences of other participants who had successfully overcome a particular barrier led to the sharing of 
knowledge and the potential for further uptake of the 'solution'. For example, in one case a participant described that despite their high solid fuel bill they often found their home still to be too cold. Another participant/neighbour suggested that the existing open fire place could well be the main causal factor and explained that faced with the same problem they had purchased a wood burning stove which provided substantial heat comfort much more affordably. This provided the participant with information and local experience needed to solve their issue.

\subsection{Results and Discussion}

As described in the previous section, the facilitators in both the DBA workshops and especially in the focus groups catalysed stories and recorded them. These stories and their case studies formed a major part of the project's communication strategy and were utilised heavily in the promulgation material. Local families, their members and participants supported the workshops and focus groups. By way of example of this activity and its outcomes Table 3 and 4 present case studies of 6 families derived from their stories that were originally articulated at focus groups (actual names have been pseudonymised to preserve participant anonymity). These examples are provided to reflect the breadth of the participants activities and their stories. The stories and their case studies provided substantial local narrative for repeat promulgation material. The case studies combined the local message with meaningful metrics as guidance so that the community could envisage the low carbon behaviour or practice and the potential impact in respect of decarbonisation, including measures relating to waste, transport and household energy practices. 
The aim was to foster stories whatever the genre. Interestingly horror stories and hero stories did not really feature at any of the workshops or focus groups. In Tables 3 and 4 it could be argued that the case studies numbered 1 and 5 are, in some senses hero stories as they have a technological focus, but it should be borne in mind that the case studies are a summary of a story. In each case the story included local actors modelling the low carbon practice, and more complex and nuanced solutions exhibiting a clear interplay between the social and the technical. Table 1 clearly shows these to be the characteristics of learning stories.

\section{Table 3: Case studies derived from stories (actual names replaced)}

Tables 3 and 4 demonstrate the use of action research in sampling the stories that it generates and further developing and socialising their value through the utilisation of shortened case studies. The core aspect of social learning theory relevant to our methods (Table 2) relates to the enabling of observers to learn about and experience different aspects of low carbon behaviour in a variety of pertinent ways. Residents or observers can identify, or compare themselves, with the storyteller and gain an understanding of why they made such choices. Participatory action research involves participants in the intervention outcomes and thus the stories and their case studies are a strong example of this form of action research. Adaptive management prescribes that participants tell stories based on the low carbon transition required in the intervention and that these stories and their case studies are utilised to feedback to other residents in order

to enhance their own low carbon transition. Social and situated learning approaches are based very much in the story context that the storyteller 
portrays; something clearly demonstrated in this paper by each case study. In the participatory interventions of this research the local context of the storyteller is shared by the observer and this therefore provides actionable local and solution-orientated messaging which carries with it the potential to drive sustainable transition. Place based science (as opposed to technical, expert-led science) is critical to this type of intervention and this emerges in the stories and their case studies in Table 3 and 4 with easily understood low carbon guidance. In analytic deliberation the participant becomes involved in - and a part of - the analysis, and this was one of the aims of the intervention's audit workshops. In the workshops participants evaluated the ecological footprint surveys and produced the estimates such that the overall EF calculation was very much owned by the community. The focus groups were the most important part of the reinterpretation efforts within this intervention. They adapted the technical measurement presented by the audit workshops and translated it into local narrative. This narrative was generated within stories and other dialogue and generated inter alia the 6 example case studies in Table 3 and 4.

\subsection{Car Transport}

The notion of people being 'locked' into particular travel practices and patterns by a range of factors including social, physical and economic conditions is well recognised in both policy and academic literature. For example, EU (2012, p4) argues that: "Sociological theories focus on the structure surrounding the individual, rather than the individual themselves" and that this has strong relevance with respect to transport related behaviour. This notwithstanding, in the research carried out for this paper a $28 \%$ reduction in the average resident's reported car transport EF was facilitated (Figure 3 And Table 5) by the 
intervention over a four year period, indicating that it is possible to break free from seemingly rigid habits provided that appropriate encouragement, guidance, support and empowerment are developed/made available..

\section{Table 4: Case studies derived from stories (actual names are replaced)}

\section{Figure 3: Car EF over four years}

With standard deviations of similar value to the means and large ranges the per capita ecological footprint clearly demonstrates significant variation amongst residents, as shown in Table 5. Reductions in mean car EF per capita resulted from some mode substitution through uptake of public transport which showed substantial increases, albeit from a low starting basline. The more significant part of the reduction however was due to a diminishment in car distances travelled which was accounted for primarily by a reduction in short car journeys taken.

\section{Table 5: Sample variables for car transport EF per capita}

\subsection{Household Waste}

The mean reported waste EF per resident is shown to decrease by 47\%, (Table 6 and Figure 4) over the four years from an initial mean value of over one gha (global hectares). The variance in waste EF between residents can be seen in the magnitude of the range of variables.

Figure 4: Total waste EF over four years 
Within this decrease the waste EF's of recycled and landfill waste were further subdivided and calculated and data (see Carragher (2011, p210-211) for a more detailed treatment and analysis of these data).

\section{Table 6: Sample variables for total waste EF per capita}

\subsection{Household Energy}

Figure 5 shows that mean reported household-energy EF per capita estimations, corrected for degree day differences, reduced over the four years. Table 7 shows the sample variables, with mean household energy EF over the 4 year intervention reducing by $36 \%$ - reflecting a considerable downward shift in the reported emissions of Ballina residents.

\section{Figure 5: Household energy EF per capita over four years}

The variance in personal consumption is underlined in year 1 in Table 7 which shows a range of 9 gha. The 95\% confidence intervals, in Figure 5, are therefore extremely useful as they remove the more significant outliers. Though this reduces the calculated means it enables analysis of the bulk of the sample. The Table also shows that the range and $\sigma$ reduce significantly over the four years of the study. An analysis of each of the household energy EF components takes place in Carragher (2011, p200-208) in order to investigate this reduction further.

\section{Table 7: Sample variables for household energy EF per capita}

This research uniquely combines the mixed methods identified above and applies them in an intervention to a commuter settlement over 4 years. The generation of local narrative through the storytelling and case study devices 
fostered using DBA were the main measures within this intervention. The measures within the intervention supported the reduction of this community's reported EF by $28 \%$ over 4 years. In this research, workshops and focus groups were effectively employed as conduits of social learning, based on the local consumption, circumstances and the options available. A diversity of types of events as outlined in Beckley et al. (2006) and Slocum (2003) could be organised for other settlements based on their attributes, circumstances and options available. The events organised in this research suited the local attributes and actors present in the community and may be transferrable elsewhere. A more complete profiling and screening of community attributes would further help in providing depth of insight and the basis to assess the full gamut of suitable community attributes.

Mixed methods approaches are more time intensive than conventional interventions that have often spent heavily on marketing and communications approaches and services. A notable example is the Power of One campaign (described briefly earlier in the introductory section of this paper) which directly impacted the emissions of just 13 households on a multi-million Euro budget. Political governance is further challenged by short rotation systems prioritising policy and action over relatively short time scales. These short time scales are mismatched with the challenges society faces in relation to sustainability issues such as climate change. In order to improve scalability - and in relation to integrating national government and local level action - policy needs to take advantage of commonalities in attributes and infrastructure which exist across many communities, to enhance the chances of successful outcomes. The profiling 
and screening utilised in the current study proved useful in identifying the common attributes, capacity and infrastructure which need to be leveraged and supported in order to provide an economy of scales and increase the impact of such approaches. It is likely that attributes will vary on a community by community basis and thus the customisation of approaches is paramount for other similar interventions to gain traction and be effective in practice.

Based on the substantial reductions in the ecological footprint reported in this paper, and its associated resource consumption and related emissions funding remits at the national level, there is inevitably a need to look beyond one and two years in order to provide support for interventions over a longer time frame such as 4 years and upwards. Such time scales are more appropriate to deeper impacts at the social level and can hopefully generate even greater progress in sustainable transition.

\subsection{Conclusions}

The reported ecological footprint values of this community are estimates and do not provide absolute values. The longitudinal nature of the EF estimates however provide a relative trend of the the community's overall footprint. There is strong evidence, for the test community in this research, that modelling through storytelling, facilitated by DBAs, can contribute to substantial decarbonisation of lifestyles. Relative evidence of such lifestyle trends needs further research as it is a significant challenge to align cause and effect in a 'living laboratory' type situation. 
The research approach utilises social and situated learning and leverages the way in which individuals learn though interactions with others in social and other settings through reflection on how other people reduce the carbon intensity of their lifestyles. There should be important gains to be made through the transferability of the mixed research methods of this research intervention. The main focus was the generation of local narrative in order to catalyse sustainable transition within a settlement. The main outputs from this process were stories and related case studies which in effect modelled local behaviour and practices providing local and solution orientated ideas and messaging for sustainable transition. The methods utilised require time, resources and discipline for active listening and this is essential as it is through this supportive listening and storytelling that facilitators can understand contexts. On this evidence, stories backed up with short case studies are a useful approach to modelling low carbon behaviour and practices. They form a more easily understood and potent message than technologically-based messages which are the universal approach for experts to date. The use of DBAs to generate local narrative and stories proved useful in this research intervention and given the significant energy, waste and transport reductions recorded could prove useful to policy makers and researchers in relation to enhancing sustainable transition.

It is apparent that both national government and local authorities need to empower citizens to a greater extent than is happening currently in Ireland. Further research aiming to learn from interventions, similar to those reported here, is required in order to arrive at a point where government-led and local level action can be integrated so as to benefit and contribute practicably towards 
sustainable transition. Further research also needs to focus on revealing where scaling related method and progress could be achievable. This will require the support of experienced facilitators adept in multiple methods of DBA.

From the stories, it was clear that behaviour change was not only an activity undertaken by participants to improve their lifestyle, but also provided a memorable and potentially emotive experience. Within the workshops and focus groups satisfaction was gained from EF measurement, learning new skills, recounting stories and from gaining a more sustainable lifestyle. Case studies are a useful way to transmit the learning of the story and to remind participants of the stories after the event. They also provide recognition and legitimacy for the storyteller/case study subject.

There were multiple lessons that this intervention provided such as the necessity of profiling and screening together with early recruitment of stakeholders and community based organisations for such participatory research. Embedding the intervention process in the community and engendering ownership and procedural justice is key. The approaches of research funding agencies need to be flexible enough to cater for the challenges of community-based research and the inconsistencies of available voluntary commitments. All parties to the research - the researcher, the funding agencies and the communities, oftenhave very different perspectives, aspirations and expectations. It is clear that flexibility when scoping and tasking the research should be incorporated to address this potential challenge as far as possible. The activities and path taken by action research is difficult to predict and methods 
can therefore benefit from adaptive management. Those designing similar research need to be aware of researcher, stakeholder and participant competencies. Ultimately this means that profiling and selection of suitable communities should be completed as early as the funding application and research design stage.

\section{Acknowledgements}

This research was funded by the Irish Research Council through their Irish

Research Council for Science Engineering and Technology Postgraduate Scholarship. Supplementary funding from the Local Agenda 21 Partnership Fund via North Tipperary County Council, the EPA and ENFO were also supportive. The support and participation of those in the community is also acknowledged.

\section{References}

Baldwin, C., Tan, P.L., White, I., Hoverman, S. \& Burry, K., 2012. How scientific knowledge informs community understanding of groundwater. Journal of Hydrology, 474, 74-83.

Barber, B.R., 1984. Strong Democracy: Participatory Politics for a New Age. University of California Press, Berkeley.

Beckley, T.M., Parkins, J.R. and Sheppard, R.J., 2006. Public Participation in Sustainable Forest Management: A Reference Guide. Sustainable Forest Management Network, Edmonton, Alberta.

Berkes, F., 2009. Evolution of co-management: Role of knowledge generation, bridging organisations and social learning. Journal of Environmental Management, 90, 1692-1702.

Berry, S., Sharp, A., Hamilton, J. \& Killip, G., 2014. Inspiring low-energy retrofits: the influence of "open home" events. Building Research \& Information, 42, 4, 422433.

Binder, D.M. and Bourgeois, M.J., 2006. Direct and indirect effects of group discussion on consensus. Social Influence, 1, 4, 249-264. 
Bingham, S., 2007. Climate change - a moral issue. Chaper 9 in Moser, S. C. and L. Dilling, eds., (2007) Creating a Climate for Change: Communicating Climate Change and Facilitating Social Change. Cambridge University Press, Cambridge.

Boreux, V., Born, J. \& Lawes, M.J., 2009. Sharing ecological knowledge: opportunities and barriers to uptake. Biotropica, 41, 532-534.

Bremer, S. \& Funtowicz, S., 2015. Negotiating a place for sustainability science: Narratives from the Waikaraka Estuary in New Zealand. Environmental Science \& Policy, 53, 47-59.

Carragher, V., 2011. Using An Ecological Footprint To Operate And Maintain A Short-Term Self Regulating And Community Based Environmental Programme. $\mathrm{PhD}$ thesis, Chemical and Environmental Sciences, University of Limerick, Limerick. Available here:

http://ulir.ul.ie/bitstream/handle/10344/1955/2011_Carragher,\%20Vincent.pdf?sequence $=6$.

Carragher, V., Lockwood, H. and McCormack, S., 2017. Identification and review of factors which drive sustainable consumption. EPA Report available at: https://www.tcd.ie/civileng/assets/documents/Carragher\%20et\%20al\%20201 7\%20Review\%20Final.pdf.

COM, 2017. Covenant of Mayors searchable map. Available at http://www.covenantofmayors.eu/participation/covenant map en.html

Corburn, J., 2009. Toward the Healthy City: People, Places, and the Politics of Urban Planning. MIT Press, Cambridge.

CSO, 2012. Census 2011, Population Classified by Area. Central Statistics Office (Cork).

CSO, 2016. Environmental Indicators Ireland. Central Statistics Office (Cork).

Daniels, S.E. and Cheng, A.S., 2004. Society and Natural Resources; A Summary of Knowledge. Prepared for the $10^{\text {th }}$ International Symposium on Society and Natural Resource Management. Modern Litho, Missouri.

DCENR (2015). Ireland's Transition to a Low Carbon Energy Future 2015-2030, Department of Communications, Energy and Natural Resources, Dublin. Available at: http://www.dccae.gov.ie/enie/energy/publications/Documents/2/Energy\%20White\%20Paper\%20\%20Dec\%202015.pdf

DECLG, 2012. Our Sustainable Future. Department of the Environment, Community and Local Government, Dublin.

DEFRA, 2007. Mobilising individual behavioural change through community initiatives: Lessons for climate change. Department for Environment, Food and Rural Affairs, London. 
Doyle, R. and Davies, A.R., 2013. Towards sustainable household consumption: exploring a practice oriented, participatory backcasting approach for sustainable home heating practices in Ireland. Journal of Cleaner Production, 48, 260-271.

Dryzek, J.S., 2000. Deliberative Democracy and Beyond. Oxford University Press, Oxford.

Duffy, B., Hall, S. \& Williams, M., 2005. Who Do You Believe, Trust in Government. Ipsos MORI, London.

Dunwoody, S., 2007. The challenge of trying to make a difference using media messages. Chapter 5 in Moser, S. C. and L. Dilling, eds., (2007) Creating a Climate for Change: Communicating Climate Change and Facilitating Social Change. Cambridge University Press, Cambridge.

EEA, 2011. The European environment - state and outlook 2010: assessment of global megatrends. European Environment Agency, Copenhagen.

EEA, 2016. The European environment - state and outlook 2015: assessment of global megatrends. European Environment Agency, Copenhagen. Available here: http://www.eea.europa.eu/soer

EPA, 2017a. GHG Emission Projections Report, 2016-2035. Environmental Protection Agency (Wexford). Available at:

https://www.epa.ie/pubs/reports/air/airemissions/ghgprojections/EPA_2017_ GHG_Emission_Projections_Summary_Report.pdf

EPA, 2017b. What are Ireland's greenhouse gas emissions? Environmental Protection Agency, Wexford, Ireland. Available at:

http://www.epa.ie/climate/communicatingclimatescience/whatisclimatechange /whatareirelandsgreenhousegasemissionslike/

ESRI, 2013. Advertising to boost energy efficiency: the Power of One campaign and natural gas consumption. The Economic and Social Research Institute, Dublin.

EU, 2012. Science for Environment Policy Future Brief: Green Behaviour. Issue 4. Science Communication Unit, the University of the West of England, Bristol.

Eurostat, 2014. Available at: http://ec.europa.eu/eurostat/statisticsexplained/images/e/ee/Modal_split_of_inland_passenger_transport\%2C_2013_ \%28 $\% 29 \_\% 28 \% 25$ of_total_inland_passenger-km\%29_YB16.png.

Fernandez-Gimenez, M.E., Ballard, H.L. \& Sturtevant, V.E., 2008. Adaptive management and social learning in collaborative and community-based monitoring: a study of five community-based forestry organisations in the western USA. Ecology and Society, 13, 2, 4. 
Forde, C., O' Byrne, D., O'Connor, R., Ó hAdhmaill, F. and Power, C., 2015. The Changing Landscape of Local and Community Development in Ireland: Policy and Practice, Conference Proceedings, University College Cork, Cork.

Garmendia, E. \& Stagl, S., 2010. Public participation for sustainability and social learning: Concepts and lessons from three case studies in Europe. Ecological Economics, 69, 8, 1712-1722.

Hajjar, R. and Kozak, R.A., 2015. Exploring public perceptions of forest adaptation strategies in Western Canada: Implications for policy-makers. Forest Policy and Economics. http://dx.doi.org/10.1016/j.forpol.2015.08.004.

Hori, S., Kondo, K., Nogata, D., and Ben, H., 2013. The determinants of household energy-saving behavior: Survey and comparison in five major Asian cities.

Energy Policy, 52, 354-362.

Jackson, S., Tan, P.L., Mooney, C., Hoverman, S. \& White, I., 2012. Principles and guidelines for good practice in Indigenous engagement in water planning. Journal of Hydrology, 474, 57-65.

Janda, K.B. \& Topouzi, M., 2013. Closing the loop: Using hero stories and learning stories to remake energy policy. Proceedings of ECEEE Summer Study, European Council for an Energy-Efficient Economy, Presqu'île de Giens, France.

Janda, K. B. \& Topouzi, M., 2015. Telling tales: using stories to remake energy policy. Building Research \& Information, 43, 4, 516-533.

Kainer, K.A., DiGiano, M.A., Duchelle, E., Wadt, L.H.O., Bruna, E. \& Dain, J.L., 2009. Partnering for greater success: local stakeholders and research in tropical biology and conservation. Biotropica, 41, 555-562.

Keen, I., 2003. Aboriginal Economy and Society: Australia at the Threshold of Colonisation. Oxford University Press, Melbourne.

Lejano, R.P., Tavares-Reager, J. and Berkes, F., 2013. Climate and narrative: Environmental knowledge in everyday life. Environmental Science and Policy, 31, 61-70.

Luyet, V., Schlaepfer, R., Parlange, M.B. and Buttler, A., 2012. A framework to implement Stakeholder participation in environmental projects. Journal of Environmental Management, 111, 213-219.

Mackenzie, J., Tan, P.L., Hoverman, S. \& Baldwin, C., 2012. The value and limitations of Participatory Action Research methodology. Journal of Hydrology, $474,11-21$.

Measham, T.G., 2009. Social learning through evaluation: a case study of overcoming constraints for management of dryland salinity. Environmental Management, 43, 1096-1107. 
McKenzie-Mohr, D., 2000. Quick Reference; Community-Based Social Marketing. Available from www.cbsm.com.

McNeeley, S. \& Huntington, 0.., 2007. Postcards from the (not so) frozen North: talking about climate change in Alaska. Chapter 8 in Moser, S. C. and L. Dilling, eds., (2007) Creating a Climate for Change: Communicating Climate Change and Facilitating Social Change. Cambridge University Press, Cambridge.

Moezzi, M. \& Janda, K. B., 2014. From "if only" to "social potential" in schemes to reduce building energy use. Energy Research \& Social Science, 30-40.

Moser, S.C. \& Dilling, L., 2007. Toward the social tipping point: creating a climate change. Chapter 32 in Creating a Climate for Change. Cambridge University Press, Cambridge.

Mourik, R., van Summeren, L.F.M., S., Rotmann, S. \& Breukers, 2015. Did you behave as we designed you to? Deliverable 3A, Monitoring and evaluating behavioural change in Demand Side Management: A Positioning paper. IEA DSM Task 24, 42 .

Munday, M., Bristow, G. and Cowell, R., 2011. Wind farms in rural areas: How far do community benefits from wind farms represent a local development opportunity? Journal of Rural Studies, 27, 1 - 12.

NESC, 2012. Social and Behavioural Aspects of Climate Change, Background Paper No.3. National Economic and Social Council, Dublin.

NESC, 2013. Ireland and the climate change challenge. National Economic and Social Council, Dublin.

Pahl-Wostl, C., 2006. The importance of social learning in restoring the multifunctionality of rivers and floodplains. Ecology and Society, 11, 1, 10.

Peters, M., Fudge, S. and Hoffman, S., 2013. The persistent challenge of encouraging public participation in the low-carbon transition. Carbon Management, 4, 4, 373-375.

Petts, J., 2006. Managing public engagement to optimise learning: reflections from urban river restoration. Human Ecology Rev.iew, 13, 2, 172-181.

Ramaswami, A., Main, D., Bernard, M., Chavez, A., Davis, A., Thomas, G. \& Schnoor, K., 2011. Planning for low-carbon communities in US cities: a participatory process model between academic institutions, local governments and communities in Colorado. Carbon Management, 2, 4, 397-411.

Randall, R., 2009. Loss and climate change: the cost of parallel narratives. Ecopsychology, 1, 3, 118-29. 
Reed, M.S., 2008. Stakeholder participation for environmental management: A literature review. Biological Conservation, 141, 2417-2431.

Renn, 0., 2006. Participatory processes for designing environmental policies. Land Use Policy, 23, 1, 34-43.

Rotmann, S.B., Goodchild, B. \& Mourik, R., 2015. Once upon a time... How to tell a good energy efficiency story that "sticks". In Proceedings of the ECEEE Summer Study, 1-6 June 2015. European Council for an Energy-Efficient Economy, Stockholm, Sweden.

Satterfield, T., Slovic, P. \& Gregory, R., 2000. Narrative valuation in a policy judgment context. Ecological Economics, 34, 315-331.

Shackleton, C.M., Cundill, G. \& Knight, A.T., 2009. Beyond just research: experiences from Southern Africa in developing social learning partnerships for resource conservation initiatives. Biotropica, 41, 563-570.

Slocum, N., 2003. Participatory Methods Toolkit A practitioner's manual. King Baudouin Foundation.

Warren, C.R. and Mc Fayden, M., 2010. Does community ownership affect public attitudes to wind energy? A case-study from south-west Scotland. Land Use Policy, 27, $204-213$.

Wilner, K., Wiber, M., Charles, A., Kearney, J., Landry, M. \& Wilson, L., 2012. Transformative learning for better resource management: the role of critical reflection. Journal of Environmental Planning and Management, 55, 10, 13311347.

Wustenhagen, R., Wolsink, M. and Burer, M.J., 2007. Social acceptance of renewable energy innovation: An introduction to the concept. Energy Policy, 35, 2683-2691. 